\title{
Is home monitoring of lung function worthwhile for children with asthma?
}

\author{
P D Sly, F Flack
}

In this issue of Thorax Kamps et al point out that current guidelines for the management of asthma in children frequently advocate the use of home monitoring of lung function. This is supposed to provide an objective measurement of the status of the child's asthma that can be used to guide therapy. This situation has come about partly as a "trickle down" from guidelines for managing asthma in adults and partly through a recognition that many children have a poor ability to perceive and accurately report airway obstruction. $^{2}$ An objective measure of asthma severity should therefore allow for more effective asthma management with a reduction in mortality and morbidity. Home monitoring with a portable peak expiratory flow (PEF) meter has been advocated as such a measure and included in many asthma management plans. In theory, PEF monitoring can provide both an indication of the degree of airway obstruction and an indication of variability of the obstruction. The rationale for using PEF variability is that it correlates, although weakly, with asthma symptoms and airway hyperresponsiveness. ${ }^{3-6}$ Portable PEF meters suitable for use in the home have been available for some time.

Despite the widespread incorporation of PEF monitoring into paediatric asthma management guidelines, no convincing evidence has been produced either to validate its use or to show that it improves asthma management. There is, however, a growing body of evidence to the contrary. Studies have shown that changes in PEF do not always reflect changes in lung function. We compared PEF measured with a portable PEF meter with that measured with an electronic spirometer under controlled conditions in a boarding school and found frequent discrepancies between PEF and "true lung function". ${ }^{7}$ During this study PEF monitoring detected only six out of 15 episodes of clinically important deterioration in lung function. Clinically significant falls in PEF were found to occur in the absence of changes in lung function, and significant falls in lung function occurred that were not reflected by a fall in $\mathrm{PEF}^{7}$ Other studies have shown that correcting for errors in PEF would dramatically change the treatment choices in self-management plans. ${ }^{8}$

$\mathrm{PEF}$ is a relatively insensitive measure of airway calibre. With the advent of inexpensive portable spirometers, forced expiratory volume in one second $\left(\mathrm{FEV}_{1}\right)$ may be a better measure of lung function for home monitoring. However, there is more to home monitoring of lung function than the accuracy of the instrument used. Other potential problems are compliance with the monitoring and technical expertise in performing lung function manoeuvres. In adults, short term compliance with twice daily measurements is quite good but is down to $33 \%$ by 12 months. ${ }^{9}$ This finding came from a well motivated study group enrolled in a clinical trial who had taken part in an asthma education programme. In this issue of Thorax Wensley and Silverman ${ }^{10}$ show that children are capable of maintaining the technical quality of their manoeuvres over 4 months but, like adults, their compliance decreases after 4 weeks. This paper adds to the evidence produced by Pelkonen $e t ~ a l^{11}$ that children aged 5-10 years can reliably perform reproducible spirometric tests during home monitoring. However, the question remains: what evidence is there that measuring lung function regularly will improve asthma management?

A Cochrane review of health outcomes of selfmanagement education and regular medical review assessed 25 trials in adults. ${ }^{12}$ Self-management education, which involved self-monitoring by either PEF or symptoms, resulted in reduced hospital admissions, emergency visits, unscheduled visits to the doctor, days off work or school, and nocturnal asthma. No difference in outcomes was noted whether PEF or symptom monitoring was used. The factors that have been shown to improve health outcomes are self-management education that includes a written action plan, self-monitoring (PEF or symptoms), and regular medical review.

In children one study showed that regular monitoring of PEF did not provide any additional benefit to daily recording of symptoms and use of bronchodilators. ${ }^{13}$ Another study has shown that a self-management education programme which did not include home monitoring of lung function was able to reduce the number of emergency room visits. ${ }^{14}$ There is therefore currently no evidence that home monitoring of lung function by PEF or spirometry improves asthma management.

Further compounding this problem are the data presented in this issue of Thorax by Kamps et al. ${ }^{1}$ They show that the information provided in a PEF diary by apparently well motivated children with asthma and their families is unreliable. Not only do patients cheat by inventing PEF values, but they also misreport the readings they have made. In this 4 week study the actual compliance, judged by covert monitoring with a microchip, was substantially lower $(77.1(20.5) \%)$ than the reported compliance on the PEF diary (95.7 (9.1)\%). In the first week of study only $56 \%$ of PEF readings reported in the diary were accurate, with incorrectly recorded and fabricated values accounting for the discrepancies. The situation was marginally better in the half of the study group who were explicitly advised that the PEF diaries were going to be used to guide adjustments to their asthma management.

The findings of Kamps et al may go a long way to explaining why home monitoring of lung function has not been shown to improve asthma management. Our patients are almost certainly telling us that this is just not that important. While portable PEF meters have their problems, the data presented by Kamps et al ${ }^{1}$ strongly suggest that the need to pursue optimal methods of home monitoring of lung function should be questioned.

PETER D SLY FELICITY FLACK

Division of Clinical Sciences,

Institute for Child Health Research and Centre for Child Health Research, University of Western Australia,

Perth,

Australia

peters@ichr.uwa.edu.au

1 Kamps AWA, Roorda RJ, Brand PLP. Peak flow diaries in childhood asthma are unreliable. Thorax 2001;56:180-2.

2 Sly PD, Landau LI, Weymouth R. Home recording of peak expiratory flow rates and perception of asthma. Am $\mathcal{F}$ Dis Child 1985;139:479-82.

3 Sly PD. Relationship between change in PEF and symptoms: questions to ask in paediatric clinics. Eur Respir f Suppl 1997;24:80-3S. 
4 Brand PL, Duiverman EJ, Postma DS, et al. Peak flow variation in childhood asthma: relationship to symptoms, atopy, airways obstruction and hyperresponsiveness. Dutch CNSLD Study Group. Eur Respir f 1997;10:1242-7. 5 Gern JE, Eggleston PA, Schuberth KC, et al. Peak flow variation in childhood asthma: a three-year analysis. F Allergy Clin Immunol 1994;93: $706-16$

6 Clough JB, Williams JD, Holgate ST. Effect of atopy on the natural history of symptoms, peak expiratory flow, and bronchial responsiveness in 7 - and 8 -year-old children with cough and wheeze. A 12-month longitudinal study. Am Rev Respir Dis 1991;143(4 Pt 1):755-60 (published erratum 1992;146:540).

7 Sly PD, Cahill P, Willet K, et al. Accuracy of mini peak flow meters in indicating changes in lung function in children with asthma (see comments). BMF 1994;308:572-4.

8 Miles JF, Tunnicliffe W, Cayton RM, et al. Potential effects of correction of inaccuracies of the mini-Wright peak expiratory flow meter on the use of an asthma self-management plan. Thorax 1996;51:403-6.
9 Cote J, Cartier A, Malo JL, et al. Compliance with peak expiratory flow monitoring in home management of asthma. Chest 1998;113:968-72

10 Wensley D, Silverman $M$. The quality of home spirometry in school children with asthma. Thorax 2001;56:183-5.

11 Pelkonen AS, Nikander K, Turpeinen M. Reproducibility of home spirometry in children with newly diagnosed asthma. Pediatr Pulmonol 2000;29:34-8.

12 Gibson PG, Coughlan J, Wilson AJ, et al. Self-management education and regular practitioner review for adults with asthma. Cochrane Database of Systematic Reviews 2000:CD001117.

13 Uwyyed K, Springer C, Avital A, et al. Home recording of PEF in young asthmatics: does it contribute to management? Eur Respir f 1996;9:872-9.

14 Ronchetti R, Indinnimeo L, Bonci E, et al. Asthma self-management programmes in a population of Italian children: a multicentric study. Italian Study Group on Asthma Self-Management Programmes. Eur Respir $\mathcal{f}$ 1997;10:1248-53.

\title{
Systemic effects of inhaled corticosteroids are milder in asthmatic patients than in normal subjects
}

\author{
L Fabbri, R Melara
}

Inhaled glucocorticosteroids are the first line antiinflammatory agents for the long term treatment of asthma. ${ }^{12}$ They are also frequently prescribed in chronic obstructive pulmonary disease (COPD), ${ }^{3}$ even if their efficacy in this condition is still controversial. ${ }^{4}$

The inhalatory mode of administration maximises the delivery to the airways and minimises the systemic delivery of glucocorticosteroids, increasing the therapeutic ratio. ${ }^{5}$ However, long term treatment of asthma ${ }^{6}$ and $\mathrm{COPD}^{7}$ with inhaled corticosteroids is associated with a significant risk of dose related systemic adverse events. This risk is particularly worrying in patients with moderate to severe asthma who require continuous treatment with high dose inhaled steroids to keep the disease under control and to prevent exacerbations, and who also require recurrent cycles of systemic glucocorticosteroids to treat exacerbations. $^{23}$ The biomarkers most frequently used to assess systemic availability of glucocorticosteroids are serum cortisol, urinary cortisol and its metabolites, and serum osteocalcin. The most worrying potential systemic effects are osteoporosis, growth suppression, adrenal insufficiency, cataracts, and glaucoma. ${ }^{8}$

Several studies have assessed the systemic activity of inhaled steroids by looking at short term effects in normal subjects and/or mild asthmatics, with the assumption that results obtained in normal subjects could be transferred to more obstructed subjects such as those with moderate to severe asthma. ${ }^{8}$ By contrast, recent studies have clearly shown that the systemic availability of inhaled glucocorticosteroids, and particularly fluticasone, is substantially less in patients with moderate to severe asthma than in normal subjects, ${ }^{9}$ which suggests that results obtained in normal subjects (and perhaps asthmatic subjects with normal lung function) should not be used to predict systemic activity in patients with moderate to severe asthma. Inhaled steroids such as budesonide and fluticasone are potent locally and are almost entirely transformed into inactive metabolites in the liver, so that their systemic bioavailability is almost entirely due to their absorption by the lung. ${ }^{5}$ The absorption through the lung depends on several factors, including mode of inhalation, particle size of the aerosol, and degree of airflow limitation of the subjects examined.
In this issue of Thorax Harrison et $a l^{10}$ report that the systemic availability of inhaled fluticasone is higher in normal subjects than in patients with moderate to severe asthma, confirming that normal subjects are more sensitive than asthmatics to the systemic effects of this inhaled glucocorticosteroid. In fact, they found that treatment for 7 days with $1 \mathrm{mg}$ /day inhaled fluticasone led to lower total cortisol metabolites in normal subjects than in those with asthma. They also found that budesonide was not associated with more systemic effects in normal subjects, suggesting that differences in the response may also be related to the type of steroid used.

The study certainly provides interesting results of clinical relevance. Indeed, it is reassuring to learn that patients with moderate to severe asthma - who require larger doses of inhaled steroids and, specifically, of fluticasone which has been shown to be particularly effective in patients with moderate to severe asthma ${ }^{11}$ — are at lower risk of systemic effects. This reassuring message is in contrast to previous messages, mostly derived from studies in normal subjects, that suggested 4-5 times more systemic availability of fluticasone than of budesonide. ${ }^{8}$ The merit of the study by Harrison $e a^{10}{ }^{10}$ is that it clarifies the discrepancies of previous studies by showing that these discrepancies were the result of the different types of subjects examined and also, at least in part, of the use of different glucocorticosteroids.

The second important clinically relevant message of this study is that the larger systemic availability of fluticasone in normal subjects would suggest that fluticasone should not be used at high doses in asthmatic subjects with preserved lung function and that its dose should be reduced as lung function improves. Thus, fluticasone should be preferred in patients with moderate to severe asthma, not only because it is effective but also because it has similar systemic availability to budesonide and less effect on bone metabolism.

The larger effect of budesonide on osteocalcin suggests a higher risk of osteoporosis and fractures in patients treated with high dose budesonide. However, this effect was seen at doses of budesonide that are recommended only in patients with moderate to severe asthma. Indeed, long term treatment with regular doses of inhaled budesonide has 
recently been shown to be devoid of significant effects on growth in children with asthma. ${ }^{12} 13$

The study by Harrison $e t a l^{10}$ has some limitations and its conclusions need some consideration. The doses of fluticasone and budesonide used in the study were not equivalent as fluticasone has been shown to be at least twice as potent as budesonide and thus the better efficacy of fluticasone after 4 weeks of treatment simply reflects the different potency of the two steroids. ${ }^{258}$ Also, the two steroids were delivered through their respective devices which have markedly different characteristics. ${ }^{14}{ }^{15}$ Indeed, the smaller proportion of low fine respirable particles delivered by the Diskus might contribute to the lower lung absorption in asthmatic patients with obstructed airways. Finally, baseline values of urinary total cortisol metabolites were lower in asthmatic patients than in normal subjects as the asthmatic patients were already receiving regular treatment with inhaled steroids. Thus, it is possible that the larger systemic effect observed in normal subjects is, at least in part, related to higher baseline values, and that a similar initial effect might be observed in asthmatic subjects before starting treatment with inhaled corticosteroids.

The main message of the study of Harrison $e t a l^{10}$ is that systemic bioavailability of steroids should not be assessed in normal subjects but rather in subjects with asthma of different severity using a sensitive biomarker of systemic availability - their suggestion is to use urinary total cortisol metabolites. An important question is whether this marker is useful, not only in predicting the systemic effects associated with long term treatment with high dose steroids in a group of asthmatic subjects, but whether it may also predict the risk of systemic effects of inhaled steroids in individual patients.

Taking into account the fact that high doses of inhaled steroids are the most effective treatment for moderate to severe asthma, we badly need an early marker of systemic availability to be used in individual patients to predict the risk of systemic effects.

L FABBRI

R MELARA

Clinica di Malattie dell'Apparato Respiratorio,

Dipartimento di Scienze Mediche, Oncologiche e Radiologiche,

Università di Modena e Reggio Emilia,

Largo del Pozzo 71,

41100 Modena,

Italy

fabbri.leonardo@unimo.it

1 Sheffer AL, ed. Global strategy for asthma management and prevention. Publication no 95-3659. Bethesda: National Institutes of Health. National Heart, Lung and Blood Institute, 1995.

2 Expert Panel Report 2. Guidelines for the diagnosis and management of asthma. Publication no. 97-4051-A. Bethesda: National Institute of Health. National Heart, Lung and Blood Institute, 1997.

3 COPD Guidelines Group of the Standards of Care Committee of the BTS. BTS guidelines for the management of chronic obstructive pulmonary disease. Thorax 1997;52:S1-28.

4 Barnes PJ. Chronic obstructive pulmonary disease. N Engl F Med 2000;343: 269-80.

5 O'Byrne PM, Pedersen S. Measuring efficacy and safety of different inhaled corticosteroid preparations. F Allergy Clin Immunol 1998;102:879-86.

corticosteroid preparations. F Allergy Clin Immunol 1998;102:879-86.
6 Wong CA, Walsh LJ, Smith CJ, et al. Inhaled corticosteroid use and bone-mineral density in patients with asthma. Lancet 2000;355:1399-403. The Lung Health Study Research Group. Effect of inhaled triamcinolone on The Lung Health Study Research Group. Effect of inhaled triamcinolone on
the decline in pulmonary function in chronic obstructive pulmonary disease. N Engl f Med 2000;343:1902-9.

8 Lipworth BJ. Systemic adverse effects of inhaled corticosteroid therapy: a systematic review and meta-analysis. Arch Intern Med 1999;159:941-55.

9 Brutsche MH, Brutsche IC, Munawar M, et al. Comparison of pharmacokinetics and systemic effects of inhaled fluticasone propionate in patients with asthma and healthy volunteers: a randomised crossover study. Lancet 2000;356:556-61.

10 Harrison TW, Wisniewski A, Honour J, et al. Comparison of the systemic effects of fluticasone propionate and budesonide given by dry powder inhaler in healthy and asthmatic subjects. Thorax 2001;56:186-91.

11 Noonan M, Chervinsky P, Busse WW, et al. Fluticasone propionate reduces oral prednisone use while it improves asthma control and quality of life. $\mathrm{Am}$ f Respir Crit Care Med 1995;152:1467-73.

12 Agertoft L, Pedersen S. Effect of long-term treatment with inhaled budesonide on adult height in children with asthma. $N$ Engl $\mathcal{f}$ Med nide on adult $2000 ; 343: 1064-9$.

13 The Childhood Asthma Management Program Research Group. Long-term effects of budesonide or nedocromil in children with asthma. $N$ Engl f Med 2000;343:1054-63.

14 Bisgaard H, Klug B, Sumby BS, et al. Fine particle mass from the Diskus inhaler and Turbuhaler inhaler in children with asthma. Eur Respir $\mathcal{F} 1998$; 11:1111-5.

15 Bisgaard H. Delivery of inhaled medication to children. $\mathcal{F}$ Asthma 1997;34: 443-67. 